A Informação como Instrumento de Contribuição da Contabilidade para a 1 Compatibilização no Desenvolvimento no Envolvimento Econômico e a Preservação do Meio Ambiente

\title{
A INFORMAÇÃO COMO INSTRUMENTO DE CONTRIBUICCÃO DA CONTABILIDADE PARA A COMPATIBILIZAÇÃO NO DESENVOLVIMENTO ECONÓMICO E A PRESERVAÇÃO DO MEIO AMBIENTE
}

\author{
Autores: Maisa de Souza Ribeiro \\ Mestre em Contabilidade e Controladoria pela FEA/USP \\ Eliseu Martins \\ Professor Titular do Departamento de \\ Contabilidade e Atuaria da FEA/USP e \\ Pesquisador da FIPECAFI
}

\section{DESENVOLVIMENTO ECONÔMICO SUSTENTADO}

O desenvolvimento econômico e tecnológico que se deu essencialmente após a Revolução Industrial ampliou enormemente a produção de riquezas, conquistou novos mercados de consumo, mas sempre (ou quase sempre) incorrendo no mínimo de custo possível.

Em alguns casos isso significou maximizar a utilização de todos os recursos naturais, já que eram gratuitos, ignorando serem eles renováveis ou não, ignorando ainda as conseqüências da ausência desses mesmos recursos.

(Ressalte-se que a degradação do meio ambiente não é uma conseqüência exclusiva do sistema capitalista, tendo em vista que nos países socialistas a degradação ambiental alcança níveis também alarmantes, sendo pauta de diversas discussões. Os níveis de poluição observados em função da ausência de tecnologias mínimas para preservar e proteger a natureza, entre outras razões, provocou sérios danos a estes países.)

Nunca se imputou, e ainda não se imputa à mercadoria produzida, todos os custos necessários à sua elaboração, pois a empresa agrega ao seu custo de produção somente o valor dos insumos que representam desembolso financeiro por parte da empresa, ou seja, aqueles pelos quais efetivamente ela paga. Não são computados gastos futuros que a sociedade terá para repor esses bens, menos ainda o quanto a sociedade futura sofrerá por não tê-los à disposição, quando não renováveis.

Esta situação é decorrente da utilização de um sistema tradicional de apuração de custo, cujos conceitos não abordam tratamentos pertinentes à problemática ambientai, visto que à época da elaboração destes a questão não estava em evidência, ou mesmo não existia.

Óbvio que a adequação destes conceitos às novas realidades depende das necessidades e do empenho de seus usuários. Evidenciar custos havidos com o meio ambiente não significa somente aumentar o custo dos produtos. Mas, essencialmente, divulgar ao público os efeitos decorrentes da atividade econômica sobre o meio ambiente e o consumo dos recursos naturais não renováveis. Esta é sem dúvida uma questão bastante delicada,, vez que esta divulgação poderia atestar contra o bom comportamento da empresa junto à sociedade.

Caderno de Estudos no 9 - São Paulo - FIPECAFI, Outubro de 1993 


\section{A Informação como Instrumento de Contribuição da Contabilidade para a 2 Compatibilização no Desenvolvimento no Envolvimento Econômico e a Preservação do Meio Ambiente}

\section{RESPONSABILIDADE SOCIAL DA EMPRESA}

Constatada a crescente e assustadora degradação ambiental, espontaneamente e pela pressão dos diversos segmentos que a cercam (sociedade civil, governo, clientes e fornecedores), as empresas viram-se obrigadas a incorporar aos objetivos de obtenção de lucros a responsabilidade social, visto que a continuidade de suas atividades depende de sua aceitação pela comunidade como um todo e a referida responsabilidade social abrange o bem estar da população na sua integridade.

Entenda-se que para proporcionar o bem estar da população, entre outros fatores, as empresas necessitam empenhar-se na:

- manutenção de condições saudáveis de trabalho, segurança, treinamento e lazer para seus funcionários e familiares;

- contenção e/ou eliminação dos níveis de resíduos tóxicos decorrentes de seu processo produtivo e do uso ou consumo de seus produtos de forma a não agredir o meio ambiente de forma geral;

- elaboração e entrega de produtos ou serviços de acordo com as condições de qualidade e segurança desejadas pelos consumidores.

O reconhecimento da responsabilidade social para com o meio ambiente foi a tarefa mais difícil e demorada para ser assumida pelas empresas. Esta resistência deveu-se, entre outros, aos seguintes fatores:

- altos custos: os custos para aquisição de tecnologias necessárias para contenção, redução e/ou eliminação de resíduos tóxicos, como todo processo tecnológico em desenvolvimento, eram bastantes elevados, o que gerava um forte impacto no fluxo de caixa das empresas e, numa visão superficial, sem proporcionar reflexos positivos, em termos de receitas;

- inexistência de legislação ambiental ou de rigor nas já existentes: a legislação sobre o assunto é relativamente recente, sendo que as penalidade contidas nas mais antigas não serviam como instrumento inibidor para seus infratores, dado que era menos oneroso para a empresa arcar com os encargos de uma multa do que adquirir equipamentos anti-poluentes;

- os movimentos populares não eram fortes e coesos o bastante para unir e conscientizar toda a sociedade;

- os consumidores não associavam a atuação e comportamento da empresa ao consumo de seus produtos.

Diante da realidade incontestável de ter que aplicar recursos na área ambiental, muitas empresas decidiram utilizar tais investimentos como elementos de marketing, demonstrando sua preocupação com o meio ambiente, projetando sua imagem e a de seus produtos junto à sociedade, essencialmente a seus clientes e acionistas efetivos ou potenciais. Esta política de marketing tornou-se um fator competitivo entre as empresas concorrentes.

\section{MELHORIA, ATÉ COM AUDITORIA DO MEIO AMBIENTE}

Atualmente, processos tecnológicos bem mais avançados tornam os custos dos equipamentos anti-poluentes mais acessíveis. Em muitos países, a conscientização e movimentação da

Caderno de Estudos no 9 - São Paulo - FIPECAFI, Outubro de 1993 


\section{A Informação como Instrumento de Contribuição da Contabilidade para a 3 Compatibilização no Desenvolvimento no Envolvimento Econômico e a Preservação do Meio Ambiente}

sociedade como um todo (populares, organizações de defesa do meio ambiente e governo) originaram revisões e reformulações na legislação ambiental de forma a torná-la mais ampla e rigorosa. A maciça conscientização da sociedade em muitos lugares veio afetar a imagem da empresa junto a seu público consumidor no qual passou a ser forte elemento de pressão para as empresas começarem a investir no controla ambiental, visto que dele depende a evolução do fluxo de receitas da empresa.

Neste contexto, o rigor da legislação ambiental e a ameaça de uma retaliação por parte dos consumidores foram os elementos chaves para que muitas empresas percebessem a inadiável necessidade de assumir suas responsabilidades sociais, sob o aspecto de proteção e preservação do meio ambiente. $E$ fato que a quantidade de empresas que persistem em condições inadequadas de funcionamento e de países onde essa conscientização ainda é insuficiente bastante elevada. Porém, devemos reconhecer que a evolução ocorrida é deveras relevante.

Algumas empresas criaram cargos e áreas específicas para melhor gerenciar as questões ambientais. A auditoria ambiental foi uma destas áreas, sendo que tem apresentado uma evolução crescente e de grande relevância em empresas de grande porte. Tratam-se de profissionais que tem como função estudar e monitorar a viabilidade de novos projetos, a adequação dos sistemas e equipamentos operacionais em uso, visando adequá-los ao processo de redução e/ou eliminação de poluentes, tanto sob os aspectos operacionais como sob os legais.

\section{A CONTABILIDADE}

A Contabilidade aprimorou-se ao longo dos séculos, incorporando práticas, em seguida princípios, postulados e convenções, para fazer face á evolução da sociedade e suas novas tecnologias.

A normalização da Contabilidade veio da necessidade de padronizar os procedimentos contábeis utilizados por todas as entidades, a fim de tornar as demonstrações contábeis acessíveis a todos os usuários.

A Contabilidade surgiu com a necessidade humana de quantificar riquezas, até então sem nenhum valor agregado. Na era mercantilista, os mercadores a utilizaram como instrumento para controle de estoques e avaliação do resultados. A industrialização e as inovações introduzidas no processo produtivo trouxeram a figura de um novo usuário - 0 administrador - e para satisfazer as necessidades deste surge a Contabilidade de Custos. A pulverização dos capitais das empresas, a necessidade de captar e justificar a utilização de capitais de terceiros junto às instituições financeiras, aos fornecedores e aos credores em geral dão origem a novos usuários das informações contábeis.

Percebe-se assim que a Contabilidade evoluiu o bastante para identificar, mensurar, registrar e tomar público todos os eventos de relevância envolvidos no desenvolvimento das atividades de uma empresa, com isso fornecendo fundamentos para a escolha mais acertada entre as alternativas possíveis em relação à alocação de recursos escassos e, em seguida, oferecendo elementos para avaliação dos recursos consumidos comparativamente aos rendimentos obtidos.

\section{A CONTABILIDADE E O MEIO AMBIENTE}

Neste momento, a Contabilidade, entendida como meio de fornecer informações, deverá buscar responder ao novo desafio, aparelhar-se para satisfazer aos usuários interessados na atuação das empresas sobre o meio ambiente, tendo em vista o dever de subsidiar o processo de tomada de decisão. 


\section{A Informação como Instrumento de Contribuição da Contabilidade para a 4 Compatibilização no Desenvolvimento no Envolvimento Econômico e a Preservação do Meio Ambiente}

$\mathrm{Na}$ verdade, deveria utilizar-se dos instrumentos que já possui, amoldando-os a esta nova necessidade, partindo-se do pressuposto que as empresas, voluntariamente ou não, agem para a preservação e recuperação do meio ambiente, levando-se em conta as obrigações legais que lhe são impostas. O cumprimento dessas obrigações é condicionante básica para que os órgãos públicos competentes permitam sua continuidade.

O fato é que alguns gastos realizados com a conservação do meio ambiente já são contabilizados, embora encobertos entre os custos operacionais e no capital imobilizado.

\section{Exemplo de Balanço Ambiental Publicado ${ }^{1}$}

Uma iniciativa revolucionária foi tomada por uma empresa holandesa, que tem filiais em quatorze países, inclusive Brasil - BSO/ORIGIN, uma "'joint venture"da Philips e a BSO/Behher BV, fundada em 1.976 - na área de automação. Embora pertencendo a um segmento não poluente, esta empresa publicou um balanço ambiental juntamente com suas demonstrações contábeis relativas ao ano de 1.990. Para tanto, desenvolveu uma metodologia para quantificar o impacto ambiental provocado por suas atividades, em decorrência dos gases emitidos pelos automóveis utilizados por seus funcionários, do consumo de eletricidade, de gás natural para aquecimento central e uso de aparelhos de ar condicionado em seus escritórios, além de identificar os custos ambientais relativos à coleta, incineração e poluição dos papéis utilizados e os custos de tratamento de esgotos.

O trabalho desenvolvido por esta empresa permitiu-lhe apurar, e divulgar, que as taxas ambientais, por esta recolhida aos governos dos países onde atua, não são suficientes para cobrir os custos de reparação dos danos causados ao meio ambiente global. Esta empresa verificou que sua dívida ambiental era da ordem de US\$1,2 milhão e, no entanto, menos de US\$100 mil são utilizados no pagamento de taxas de tratamento de esgotos e de resíduos. A dívida ambiental apurada representa $10 \%$ do lucro líquido desta companhia.

Nota-se que a iniciativa é pioneira, não somente pelo aspecto da divulgação do Balanço Ambiental contendo os custos ambientais decorrentes da atividade econômica, mas essencialmente pela ousadia de admitir em público sua responsabilidade pela degradação do meio ambiente e, conseqüentemente, seu passivo ambiental, como também o compromisso assumido de investir em pesquisas e estudos na área ambiental a parcela que deixou de recolher aos cofres públicos.

\section{PROCEDIMENTOS CONTÁBEIS APLICÁVEIS}

Os princípios contábeis, na forma em que estão definidos atualmente, não são estimulantes para o desenvolvimento da Contabilidade sob os aspectos de Responsabilidade Social, principalmente no que diz respeito às convenções da objetividade e do conservadorismo e ao princípio contábil da confrontação de receitas e despesas. Este último é problemático pelos aspectos relativos à dificuldade de mensuração de custos e receitas dentro do mesmo período de competência,tendo em vista que, em alguns casos, pelo fato dos desembolsos ocorrerem em momentos distintos ao da realização das receitas, não há elementos suficientes para estimativas dos gastos a serem efetivamente incorridos na área ambiental, devido às peculiaridades relativas á questão em si e aos aspectos exógenos envolvidos,como mudanças climáticas de um período a outro, diferenças nas tecnologias utilizadas entre as empresas, além do porte de cada uma.

\footnotetext{
${ }^{1}$ FAGÁ, Francisca Stella. BSO divulga seu balanço ambiental. In Jornal Gazeta Mercantil. São Paulo,18 set. 1991. p. 16.
}

Caderno de Estudos n 9 - São Paulo - FIPECAFI, Outubro de 1993 


\section{A Informação como Instrumento de Contribuição da Contabilidade para a 5 Compatibilização no Desenvolvimento no Envolvimento Econômico e a Preservação do Meio Ambiente}

As Convenções do Conservadorismo e Objetividade geram problemas na atribuição e credibilidade dos valores, essencialmente nas discussões sobre os benefícios e as responsabilidades sociais da entidade.

Em contraposição, a Convenção da Materialidade vem exigir, ainda que de forma implícita, que os gastos ambientais sejam considerados pela Contabilidade em função de sua influência e materialidade para o usuário, óbvio que respeitando a relação custo-benefício.

\section{DESPESAS E CUSTOS AMBIENTAIS}

O FAS $6^{2}$ define despesas como o consumo de recursos ou uso de ativos ou incorrência de uma exigibilidade (ou a combinação de ambos) em decorrência da entrega e produção de mercadorias, prestação de serviços ou realização de outras atividades necessárias à continuidade da empresa.

Sabendo-se que os custos e despesas destinados à preservação ambiental ocorrem em conexão com o processo produtivo e/ou em decorrência deste, entendemos que deveriam ser destacados em grupo especifico da Demonstração de Resultados do Exercício. Deveriam compor-se dos custos dos insumos e da mão-de-obra necessários à proteção, preservação e recuperação do meio ambiente, bem como da amortização dos gastos capitalizados, além das taxas de preservação ou multas impostas pelas legislações ambientais.

Os custos e despesas para preservação, proteção e recuperação ambiental, via de regra, não poderão ser associados a um processo produtivo único, como, também, dificilmente haverá condições de determinar com precisão seu exato período de competência. Porém, com os mesmos instrumentos de aproximação que a Contabilidade utiliza para alocar certos custos entre diversos períodos (depreciação, por exemplo), poderia distribuir os custos e despesas de natureza ambiental entre os períodos julgados de competência, de forma segregada.

\section{DETERIORAÇÃO DE ATIVOS}

As empresas não são apenas os agentes da poluição e degradação do meio ambiente; podem ser também suas vítimas em virtude da redução de seus patrimônios.

O FAS $6^{3}$ define o Ativo como prováveis benefícios econômicos futuros obtidas ou controlados pela empresa como resultado de um evento ou transação passada. Quando estes Ativos têm seu potencial econômico reduzido (por oscilação do valor de mercado) são tradicionalmente alvo de baixa na Contabilidade e de observações nas notas explicativas às demonstrações contábeis da empresa, conforme determinações da Comissão de Valores Mobiliários - CVM (Parecer de Orientação $n^{0}$ 15187). Contudo, quando essas reduções tiverem origens em causas ambientais, este fato poderia ser ressaltado, visando evidenciar a influência do meio ambiente sobre a empresa.

Ativos tangíveis e intangíveis, particularmente os não monetários, estão sujeitos à ação ambiental. Conseqüentemente, seus valores podem sofrer alterações por ganho ou perda do valor econômico, alterando o real potencial econômico da empresa.

\footnotetext{
${ }^{2}$ FINANCIAL ACCOUNTING STANDARDS STANDARDS BOARD- FASB. Statement Financial Accounting Concepts, $n^{0} 6-$ FAS 6. Elements of Financial Statements. 1985. p.9316

${ }^{3}$ Op. Cit. P. 9296.
}

Caderno de Estudos n 9 - São Paulo - FIPECAFI, Outubro de 1993 


\section{A Informação como Instrumento de Contribuição da Contabilidade para a 6 Compatibilização no Desenvolvimento no Envolvimento Econômico e a Preservação do Meio Ambiente}

Assim, para qualquer elemento do ativo tangível que tenha a extinção de sua vida útil acelerada ou a direta redução de seu valor econômico, no caso de terrenos ou estoques, em função de alterações do meio ambiente, deveria ser constituída, de forma segregada, uma conta de provisão para registrar sua desvalorização, evidenciando-se nas notas explicativas sua origem e natureza.

Os procedimentos e princípios contábeis atuais,orientam neste sentido, porém, com referência específica aos eventos de natureza tipicamente econômica, ou seja, oscilações do valor de mercado.

A proposta se faz no sentido de que as perdas de valor econômico, decorrentes de eventos de natureza ambiental sejam destacadas, objetivando informar aos usuários interessados a influência do meio ambiente sobre a empresa, além do valor real de seus Ativos.

Exemplos disso são certos ativos de uma empresa considerada potencialmente poluidora, instalada em área residencial, que deva transferir-se para uma área industrial por iniciativa própria ou cedendo às pressões da comunidade local, ou ainda em atendimento a exigências legais, e que não poderá levar consigo todos aqueles ativos em função de não serem transferíveis, devido a dimensões, formas da construção ou instalação, ou porque os custos de transferências são tão altos que melhor será adquirir outros. Assim, instalados e operando na condição atual possuem valor econômico e uma ampla vida útil; contudo, na expectativa da mudança, da necessidade de se adquirir substitutos, os referidos bens perdem seu valor econômico. Esta perda não ocorre no momento da mudança, mas, a partir do instante em que os fatos se constatam, já que deles não se poderá esperar benefícios futuros, dado que em breve não mais terão utilidade, pois serão desativados e sucateados antes de esgotada sua capacidade produtiva. Este é um fato que altera o valor do patrimônio da empresa e que devia ser informado ao público interessado. Logo, a provisão para desvalorização deve ser constituída e esclarecida nas notas explicativas, ressaltando-se seu caráter ambiental.

Cite-se ainda o caso da Eletropaulo, uma empresa de propriedade do Governo do Estado de São Paulo, responsável pela geração, transmissão e distribuição de energia para municípios da Grande São Paulo e Vale do Paraíba, a qual possui entre outros bens as Usinas de Traição e Pedreira no Rio Pinheiros, em São Paulo. As instalações destas usinas estão corroídas pela poluição, tendo em vista o contato diário com as águas revertidas no Rio Tietê, consagrado entre os rios mais poluídos, se não o maior, reduzindo sua capacidade de bombear água em $50 \%$ e, em conseqüência; tomando as taxas de depreciação até dez vezes superiores às de instalações similares, construídas em locais menos poluídos ${ }^{4}$.

Esta taxa de depreciação adicional também deve merecer destaque no corpo das demonstrações contábeis e menção nas notas explicativas, considerando a influência ambiental.

\section{EVIDENCIAÇÃO DOS ATIVOS AMBIENTAIS}

Com o intuito de demonstrar o empenho das empresas no processo de preservação do meio ambiente, entendemos que todos os bens possuídos por estas o, que visem a preservação, proteção e recuperação ambiental deveriam ser segregados em linha à parte das demonstrações contábeis (seja no subgrupo de Estoques ou no grupo de Ativo Permanente) de forma a transparecer suas ações e, ao mesmo tempo, permitir ao usuário avaliar tais informações, comparativamente aos demais elementos que compõem tais demonstrações.

\footnotetext{
${ }^{4}$ GAZETA MERCANTIL. Poluição obriga a Eletropaulo a gastar U\$ 12 milhões para manter equipamentos. São Paulo. 04 dez. 1991.
} 


\section{A Informação como Instrumento de Contribuição da Contabilidade para a 7 Compatibilização no Desenvolvimento no Envolvimento Econômico e a

\section{PASSIVO AMBIENTAL}

Conhecido como os prováveis sacrifícios de benefícios econômicos decorrentes de obrigações presentes de transferir ativos ou prestar serviços no futuro, como resultado de uma transação ou evento passado ${ }^{5}$, o Passivo deverá abranger todos os gastos que a empresa deverá realizar para o cumprimento de suas obrigações futuras.

Recentemente em moda, o termo "Passivo Ambiental' quer se referir aos benefícios econômicos (ou resultados econômicos), que serão sacrificados mm função da preservação, recuperação e proteção do meio ambiente, de modo e permitir a compatibilidade entre este e o desenvolvimento econômico ou em decorrência de uma conduta inadequada em relação às questões ambientais.

Os Passivos Ambientais têm origem em gastos relativos ao meio ambiente, os quais podem constituir-se em despesas do período atual ou anteriores, aquisição de bens permanentes, ou na existência de riscos de estes gastos virem a se efetivar.

É sabido, no entanto, que na maioria dos casos, tais exigibilidades são reconhecidas somente no ato da efetivação dos gastos. De acordo com os princípios contábeis, tais gastos e suas respectivas exigibilidades deveriam ser contabilizados no mesmo período em que se registrasse a receita deles decorrente de forma a se permitir a confrontação de receitas e despesas dentro do mesmo período contábil. Apesar das dificuldades de identificação e quantificação dos custos na área ambiental, são diversas as técnicas de que a contabilidade poderia estar se valendo para obter um valor, ainda que aproximado, dos custos e passivos ambientais incorridos no processo de obtenção das receitas.

Entendemos que quando os referidos estudos são de natureza preventiva, ou seja, caso seus resultados sejam aplicados no futuro em contrapartida a eventos que irão incorrer, as notas explicativas deverão ser utilizadas para dar amplo conhecimento das responsabilidades assumidas pela empresa, visto tratar-se de intenções cujas ações para sua realização, além dos referidos estudos não foram empreendidas.

Ressalte-se que os próprios estudos sobre referidos tratamentos geram Passivos Ambientais.

\section{Ativos Permanentes de Natureza Ambiental}

A aquisição de bens classificáveis no Ativo Permanente também poderá originar um Passivo Ambiental, em contrapartida a um Ativo Ambiental. Fato que ocorreria quando o processo de proteção, preservação e recuperação do meio ambiente exigisse a aquisição de equipamentos e instalações que seriam utilizados por períodos superiores ao exercício em curso.

\section{Riscos Ambientais Potenciais}

Quando correlacionados com riscos e incertezas a que a empresa está sujeita,os Passivos Ambientais adquirem as características das contingências, podendo decorrer de três situações:

- Iniciativa própria da empresa, partindo de sua consciência de responsabilidade social e envolvimento no processo de execução do "desenvolvimento sustentável";

- Reivindicações de indenização por terceiros;

\footnotetext{
${ }^{5}$ Op.Cit. p.9299.
} 


\section{A Informação como Instrumento de Contribuição da Contabilidade para a 8 Compatibilização no Desenvolvimento no Envolvimento Econômico e a Preservação do Meio Ambiente}

- Exigências de legislações ambientais.

\section{FUSÃO, CISÃO, INCORPORAÇÃO, VENDA E PRIVATIZAÇÃO}

O Passivo Ambiental tem se tomado alvo de extrema importância 6 B SUB evidenciação passa a ser exigida com maior freqüência. Os processos de cisão, fusão, incorporação, compra e venda, inclusive a privatização de empresas estatais, essencialmente aquelas consideradas poluidoras em potencial, e que são obrigadas por lei a fazer investimentos em controle ambiental, podem ser profundamente afetados em função do Passivo Ambiental.Resultando em prejuízos para os compradores, caso este Passivo seja ignorado, dado que a nova empresa ou os novos proprietários assumirão juntamente com todos os direitos que terão sobre a nova empresa,todos os riscos e responsabilidades potenciais. Haja vista ao exemplo da subsidiária do grupo francês Rhône- Poulenc - Rhodia - atuando no setor de produtos químicos, que decidiu adquirir as instalações de uma outra empresa no município de Cubatão-SP, para instalar uma nova unidade. Depois de ter concluído o processo de compra, verificou que, além das instalações, adquiriu, também gigantescos depósitos de lixo químico, os quais exigiam tratamento sob o risco de inviabilizar a continuidade operacional da empresa e sua interação com a comunidade, como também o atendimento ás exigências legais. Este é um exemplo típico de Passivo Ambiental não evidenciado e para o qual o comprador não atentou na época das negociações de compra e venda. Hoje, diz o gerente regional da Rhodia, em Cubatão: "'A análise ambiental é prioritária em qualquer operação de compra do grupo...Aqui no Brasil, laudo da CETESB vale mais do que o fluxo de caixa ${ }^{6}$

Esta é uma questão que deve ser rigorosamente observada nos processos de privatização das empresas estatais, especialmente as siderúrgicas. Segundo estimativa de uma empresa de consultoria especializada no ramo - Cetepla Tecnometal do Rio do Janeiro -, os investimentos em controle ambiental exigidos por lei para estas empresas poderão representar, em alguns casos, até $15 \%$ do potencial valor de compra, além dos riscos de serem obrigadas a parar a produção, ainda que momentaneamente, devido aos tipos e ás quantidades de poluentes produzidos, normalmente em desacordo com os padrões de qualidade suportáveis pela vida humana ${ }^{7}$.

O problema de algumas destas empresas, segundo o gerente regional da CETESB, é que possuem unidades de produção extremamente arcaicas, as quais exigem maiores volumes de investimentos em controle ambiental do que unidades mais modernas e com resultados menos eficazes ${ }^{8}$.

Segundo estudos realizados por esta empresa em 1.989, pare controlar as fontes de poluição na capacidade de produção da época, 15,9 milhões de toneladas por ano, as cinco empresas siderúrgicas do sistema Siderbrás (Companhia Siderúrgica Nacional - CSN, Cosipa, Companhia Siderúrgica de Tubarão - CST, Açominas e a Usiminas ) necessitariam investir U\$\$320.7 milhões, o que representava cerca de $3 \%$ do Patrimônio Líquido destas empresas ${ }^{9}$.

\section{INSTITUIÇÕES FINANCEIRAS}

A co-responsabilidade das instituições financeiras quando financiam empresas poluentes tem feito com que a identificação e avaliação do Passivo Ambiental ganhe importância em alguns países desenvolvidos.

\footnotetext{
${ }^{6}$ EXAME. A natureza é o negócio da década. São Paulo: Abril. 10 jul. 1991. p. ${ }^{4} 2-{ }^{4} 9$.

${ }^{7}$ GAZETA MERCANTIL, O passivo Ambiental das Estatais. São Paulo, 05 nov. 1990. p.l.

${ }^{8}$ GAZETA MERCANTIL O passivo Ambiental das Estatais. Op. Cit.

${ }^{9}$ GAZETA MERCANTIL Cinco estatais precisam investir U\$\$320 milhões em controle ambiental. Seção Meio Ambiente. São Paulo, 05 nov. 1990.
}

Caderno de Estudos no 9 - São Paulo - FIPECAFI, Outubro de 1993 


\section{A Informação como Instrumento de Contribuição da Contabilidade para a 9 Compatibilização no Desenvolvimento no Envolvimento Econômico e a Preservação do Meio Ambiente}

Nos Estados Unidos da América, os bancos têm restringido a concessão de empréstimos, principalmente às pequenas empresas que apresentem qualquer risco ambiental potencial.Os riscos destas instituições estão relacionados a dois fatores: o primeiro, que é usual no ramo do negócio é o risco da não restituição do empréstimo concedido;e o outro refere-se á possibilidade de falência da empresa e conseqüente responsabilização da instituição financeira pelos prejuízos ao meio ambiente ${ }^{10}$.

De acordo com a Associação dos Bancos Americanos, em 1.991, quase dois terços dos bancos regionais norte-americanos negaram empréstimos para empresas que apresentassem riscos ambientais, que operassem com produtos químicos perigosos, fábricas de papel e celulose e indústrias de reciclagem ${ }^{11}$.

No estado da Geórgia-EUA uma instituição financeira - Fleet Factors -concedeu um empréstimo para uma estamparia de tecidos, tomando como garantia as instalações de produção e os equipamentos. Algum tempo depois, tendo esta empresa falido, a Fleet beneficiou-se da venda de alguns de seus bens como compensação pelo empréstimo concedido. Foi, então, considerada responsável pelos rejeitas poluentes deixados pela empresa, sendo processada pela Agência de Proteção Ambiental (EPA) dos Estados Unidos, a qual requeria a cobertura dos custos de remoção de amianto e outros processos de limpeza nas instalações. De acordo com entendimento da EPA, a instituição financeira tinha condições de influenciar na administração da empresa, conseqüentemente no tratamento dispensado aos rejeitas perigosos, tendo em vista o montante do empréstimo concedido ${ }^{12}$.

Fatos como esse e a maior rigorosidade na legislação fizeram da avaliação dos riscos ambientais um quesito a mais para os processos de aprovação de empréstimos na maior parte dos bancos norte-americanos.

\section{OBRIGATORIEDADE DE EVIDENCIAÇÃO DOS PASSIVOS AMBIENTAIS}

No Brasil, o Instituto Brasileiro de Contadores - IBRACON estuda a possibilidade de as demonstrações contábeis das empresas incluírem os riscos existentes que possam causar efeitos negativos ao meio ambiente e aos seus resultados econômicos-financeiros, em decorrência de pagamentos de indenizações ou paralisação de atividades. Assim sendo, as informações sobre os riscos ambientais seriam exigidas pelos auditores por ocasião da verificação das referidas demonstrações contábeis ${ }^{13}$. Embora, esta exigência tenha sido noticiada pela Gazeta Mercantil como aplicável a partir do exercício de 1.991, obtivemos informações junto ao IBRACON de que trata-se, por enquanto, de um projeto em estudo.

Nos Estados Unidos a SEC, de acordo com o item 101 do Regulamento S-K -Descrição dos Negócios das Corporações ${ }^{14}$, as empresas estão obrigadas a informar, ainda que de forma descritiva, os efeitos materiais das legislações ambientais, nos âmbitos federal, estadual e municipal sobre seus resultados e posição competitiva, incluindo suas subsidiárias, além de estimativas de gastos ambientais estimados presentes ou futuros. O item 103 deste mesmo documento exige que as corporações evidenciem as ações ambientais, administrativas ou judiciais

\footnotetext{
${ }^{10}$ GAZETA MERCANTIL. Bancos dos EUA evitam conceder empréstimos a empresas poluidoras seção Meio Ambiente. São Paulo. 04 dez. 1991.

${ }^{11}$ Idem.

12 GAZETA MERCANTIL. Bancos dos EUA evitam conceder empréstimos a empresas poluidoras. Op.Cit.

${ }^{13}$ FREITAS, Jorge. Empresas podem ter que incluir passivo ambiental em seus balanços anuais. In: Jornal Gazeta Mercantil. São Paulo. 24 set. 1991. p. 18.

${ }^{14}$ ARTHUR ANDERSEN. CO S.C.. SIDLEY \& AUSTIN LAW OFFICES. Environmental liabilities...Is your company at risk?, 1990 - p. 6-7.
} 


\section{A Informação como Instrumento de Contribuição da Contabilidade para a 10 Compatibilização no Desenvolvimento no Envolvimento Econômico e a Preservação do Meio Ambiente}

que sejam significantes e que exercerão impacto sobre estas ou suas subsidiárias, considerando como significantes as sanções de autoridades governamentais superiores a US $\$ 100.000$, exceto obrigações relativas aos custos de limpezas ambientais: se o total de reclamos for superior a 10\% do total de ativos da corporação e suas subsidiárias, em bases consolidadas; se a ação for considerada material para os negócios da corporação ou para suas condições financeiras. Além da já mencionada necessidade de provar por que as probabilidades de ocorrência das contingências não são apenas "razoavelmente possíveis" ou "remotas" e por que seus valores não podem ser estimados.

Segundo reportagem do jornal Gazeta Mercanti ${ }^{15}$, tramitava pelo Parlamento Britânico, em janeiro de 1.992, o Projeto de Lei de Informações Ambientais e de Segurança das Empresas. Este projeto teria como propósito o acréscimo de um novo parágrafo nas demonstrações contábeis, intitulado "Segurança e Meio Ambiente" no qual deveria ser mencionado, entre outras informações as intimações para cumprimento de regulamentações expedidas pelas autoridades regulamentadoras e as condenações por transgressões ás leis ambientais e de segurança.

A partir de 1.989, na Noruega, as companhias são obrigadas a incluir em seus relatórios da Diretoria, que acompanham as demonstrações contábeis, informações sobre emissão, contaminação, detalhes sobre planos de proteção e situação da limpeza ambiental ${ }^{16}$..

No Canadá tem havido, recentemente, discussões e análises dos relatórios contábeis anuais o de administração pela Comissão de Valores Mobiliários de Ontário (Ontário Securities Commission), a qual requer a evidenciação dos efeitos operacionais e financeiros para cumprimento dos regulamentos de proteção ambiental, no tocante ao consumo de capital, ganhos e. posição competitiva para as empresas no ano fiscal e seus impactos específicos no futuro ${ }^{17}$.

\section{CONCLUSÃO}

Infelizmente, as questões ambientais só se tornaram objeto de preocupação de alguns de seus principais agentes (empreendedores de atividades econômicas poluentes), quando os níveis da poluição sobre a água, solo e ar atingiram seus patamares mais alarmantes.

Os prejuízos causados ao planeta foram todos em nome do seu desenvolvimento econômico, em nome da eliminação da pobreza reinante entre os povos. Contudo, o sistema ecológico já não suporta as agressões que lhe são feitas, qualquer que seja a razão. Logo, chegamos ao confronto entre a continuidade do desenvolvimento econômico e a do sistema ecológico.

Atingimos o estágio em que a necessária convivência do desenvolvimento econômico com o meio ambiente se torna ameaçada, embora eles não sejam mutuamente exclusivos, sendo que a questão ecológica se impõe pois se constitui na base essencial do sistema de vida no planeta. Assim sendo, só resta aos mentores do processo de desenvolvimento econômico encontrar alternativas para adaptar este às limitações do atual estado da natureza.

Na expressão Desenvolvimento Sustentável está implícito que o desenvolvimento deve satisfazer às necessidades e aspirações do presente sem comprometer a capacidade e os recursos das

\footnotetext{
15 JACK Andrew. Lei pode obrigar empresas a incluir balanço ambiental em seus relatórios anuais. In: Jornal Gazeta Mercantil. São Paulo. 21 jan. 1992.

${ }^{16}$ ONU. Comission on Transnational Corporations - Programme of Work of Intergovernamental

Working Group of Experts on International Standards of Accounting and Reporting: Discussion of Accounting and Reporting Issues Identified During of Seventh Session. Information disclousure relating of environmental measures. Report of the secretary general. Mar. 1990.

${ }_{17}$ ONU. Op. Cit.
}

Caderno de Estudos n 9 - São Paulo - FIPECAFI, Outubro de 1993 


\section{A Informação como Instrumento de Contribuição da Contabilidade para a 11 Compatibilização no Desenvolvimento no Envolvimento Econômico e a Preservação do Meio Ambiente}

futuras gerações. O que as comprometo, entre outros fatores, são os efluentes do processo produtivo de empresas poluidoras e o esgotamento dos recursos naturais.

Com isso as empresas devem adaptar e melhorar seus sistemas de produção, de forma a eliminar a quantidade de refugos poluentes.

Investimentos estão sendo realizados em algumas áreas onde os recursos naturais foram exauridos, visando tratá-las para recuperação, reflorestamentos e para destinação a um novo uso ou, pelo menos, para restaurar os aspectos estéticos.

As alternativas ainda são rudimentares e não ganharam a adesão de importantes segmentos empresariais. Contudo. as iniciativas já existentes podem conduzir, ainda que a longo prazo, a uma conscientização ampla da sociedade, inclusive do empresariado, de forma que o desenvolvimento econômico satisfaça às necessidades e aspirações presentes sem comprometimento das gerações futuras.

Cabe a todas as áreas científicas e profissionais atuar na preservação e proteção ambiental. E a área contábil pode (e deve) empenhar-se para que seus instrumentos de informação melhor reflitam o real valor do patrimônio das empresas, seus desempenhos e, ao mesmo tempo, satisfaçam as necessidades de seus usuários, inclusive sob o aspecto ambiental, dado que todas ou quase todas as alternativas que se têm apresentado para o seu controle e preservação são mensuráveis e, portanto, passíveis de contabilização e informação à sociedade.

A evidenciação dos desembolsos relacionados ao meio ambiente é de relevante importância para atender as necessidades atuais, ou seja, a informação como instrumento de combate à crescente evolução dos níveis de poluição e seus efeitos nocivos, Os investidores estarão interessados na capacidade que tem a empresa de arcar com as eventuais contingências, assim como a probabilidade de estas ocorrerem e o montante dispendido no controle ambiental. Importante, também, como instrumento para comparabilidade com outras empresas.

A confrontação das receitas e despesas dentro de seus respectivos regimes de competências é de fundamental importância na mensuração do lucro correto de cada exercício social e, conseqüentemente, do patrimônio da empresa, qualquer que seja a atividade por esta empreendida. Os diversos obstáculos que se colocam à mensuração dos gastos na área ambiental, a medida que o fato gerador destes ocorre podem ser superados pelas inúmeras técnicas estatísticas e matemáticas ao dispor da Contabilidade, pelos estudos de riscos ou mesmo com base em experiências anteriores. Antes computar no resultado valores aproximados do que omitir totalmente as despesas necessárias à sua obtenção. A omissão das despesas incorridas na área ambiental no momento em que seu fato gerador ocorre propicia a superavaliação dos resultados obtidos no período em questão e sua sub avaliação no período do desembolso.

Há de se ressaltar ainda que a obediência ao principio da confrontação entre receitas e respectivas despesas dá margem ao reconhecimento dos passivos ambientais desde o momento da incorrência do fato gerador. A evidenciação destes passivos é extremamente importante para a avaliação do real valor econômico de cada empresa, visto que via de regra envolvem montantes vultosos e, algumas vezes, comprometem a continuidade da mesma.

O valor do patrimônio da empresa também pode ser alterado em função de ações do meio ambiente sobre os bens que esta possui. Portanto, os efeitos destas ações deveriam merecer tratamento contábil, visando demonstrar o potencial econômico à disposição da entidade.

Entendemos que o fornecimento destas informações teria o poder de desencadear uma maior alavancagem no processo de controle da qualidade ambiental, pois as empresas teriam suas congêneres como parâmetros de comportamento na área ambiental, considerando-se os

Caderno de Estudos no 9 - São Paulo - FIPECAFI, Outubro de 1993 


\section{A Informação como Instrumento de Contribuição da Contabilidade para a 12 Compatibilização no Desenvolvimento no Envolvimento Econômico e a Preservação do Meio Ambiente}

diferentes portes econômicos, como também a reação do público interessado; atuaria, também como estimulo à sociedade, de forma geral, na preservação do meio ambiente.

Quanto às formas de divulgação no âmbito da Contabilidade há duas linhas de pensamento: uma que propõe à implementação de um novo relatório apenso as demonstrações contábeis, tratando somente das questões ambientais; e a outra sugere a inclusão destes dados nas atuais demonstrações mantendo o padrão já utilizado, mas apresentando contas e notas explicativas específicas. Entendemos que a segunda alternativa seria a mais adequada (pelo menos a curto prazo) já que se trata de aspectos inseridos no contexto operacional das empresas e, inclusive, para atender a necessidade imediata de a Contabilidade estar melhor informando sus usuários sobre o real valor patrimonial das empresas, sem maior perda de tempo em um processo de elaboração e implantação de um novo relatório.

\section{BIBLIOBRAFIA}

ARTHUR ANDERSEN, CO S.C., SIDLEY \& AUSTIN LAW OFFICES. Environmental liabilites... is your company at risk? 1990 - p. 6-7- 67.

EXAME. A natureza é o negócio da década. São Paulo: Abril, 10 jul. 1991. p.42 - 49.

FAGA, Francisca Stella. BSO divulga seu balanço ambiental. In Jornal Gazeta São Paulo, 18 set. 1991. p.16.

FINANCIAL ACCOUNTING STANDARDS BOARD - FASB. Statement of Financial Accounting Concepts, no. 06 - FAS 6. Elements of Financial Statements. 1985 p. 9316.

FREITAS,Jorge. Empresas podem ter que incluir passivo ambiental em seus balanços anuais. In: Jornal Gazeta Mercantil. São Paulo, 24 set. 1991. p.18.

GAZETA MERCANTIL Poluição obriga Eletropaulo a gastar US\$ 12 milhões para manter equipamentos. São Paulo, 04 dez. 1991.

O passivo ambiental das estatais. São Paulo, 05 nov. 1990. p. 1.

Cinco estatais precisam investir USS 320 milhões em controle Seção Meio Ambiente. São Paulo, 05 nov. 1990.

Bancos dos EUA evitam conceder empréstimos a empresas poluidoras. Seção Meio Ambiente. São Paulo, 04 dez. 1991.

JACK Andrew. Lei pode obrigar empresas a incluir balanço ambiental em seus relatórios anuais. In: Jornal Gazeta Mercantil, São Paulo, 21 jan. 1992.

MARTINS, Eliseu; RIBEIRO, Maisa de Souza Ribeiro. Desenvolvimento a contabilidade ao meio ambiente, artigo. 1992.

ONU. Comission on Transnational Corporations - Programme of Work of the Intergovernamental Working Group of Experts on International Standards of Accounting and Reporting: Discussion of Accounting and Reporting Issues Identified During of Seventh Session. Information disclousure relating of environmental measures. Report of the Secretary General. mar. 1990.

Caderno de Estudos n 9 - São Paulo - FIPECAFI, Outubro de 1993 
A Informação como Instrumento de Contribuição da Contabilidade para a $\mathbf{1 3}$ Compatibilização no Desenvolvimento no Envolvimento Econômico e a Preservação do Meio Ambiente

RIBEIRO Maisa de Souza. Contabilidade e meio ambiente. Dissertação de Mestrado apresentada á Faculdade de Economia, Administração e Contabilidade da Universidade de São Paulo. 1992. 